\title{
Panorama da Gestão dos Resíduos Sólidos nos Zoológicos do Brasil
}

\author{
AUGUSTO Anderson Mendes ${ }^{1,2}$, NASSAR Cristina Aparecida Gomes ${ }^{1}$ \\ ${ }^{1}$ Programa de Engenharia Ambiental - PEA/POLI/UFRJ \\ ${ }^{2}$ Fundação RIOZOO
}

\section{Informações do Artigo}

Histórico:

Recebimento: 26 Outubro 2018

Revisão: 21 Novembro 2018

Aprovação: 21 Dezembro 2018

Palavras-chave:

Zoológicos

Resíduos sólidos

Índice de impacto de resíduos sólidos

\begin{abstract}
Resumo:
O presente artigo traça um panorama da gestão dos resíduos sólidos, com ênfase na destinação e na proposição de um índice para análise do impacto ambiental dos resíduos sólidos nos zoológicos brasileiros. O levantamento de dados foi realizado com base em informações sobre a destinação dos resíduos oriundos das seguintes atividades e/ou locais dos zoológicos: varrição; sanitários (papel higiênico); recinto dos animais (detritos); restos alimentares (humanos e animais); carcaças de animais; resíduo hospitalar (veterinária) e material de escritório. Foi constatado que grande parte dos zoológicos brasileiros não realiza a segregação adequada de seus resíduos e tendem a enviá-los para serem dispostos em aterros sanitários. $O$ cenário não varia muito se a avaliação é feita distinguindo administração pública ou privada ou diferentes categorias de zoológicos ( $A, B$ ou $C)$. $O$ índice proposto demonstrou que $65 \%$ dos zoológicos brasileiros, em relação aos resíduos sólidos, podem ser considerados geradores de impacto médio.
\end{abstract}

\section{Introdução}

Os zoológicos executam operações, que incluem as ações associadas ao: manejo e alimentação de répteis, aves e mamíferos, destino de camas, restos alimentares, dejetos, estrume e carcaças de animais; tratamento e destino de efluentes e ainda, os resíduos gerados nos cuidados veterinários, e com o público visitante e colaboradores (alimentação, sanitários, lavatórios, plásticos, vidros, metais, papéis, restos alimentares). O conjunto destas operações tende a gerar grandes quantidades de resíduos sólidos [1]. Os zoológicos são considerados elementos fundamentais na conservação e educação para um mundo mais sustentável, desta forma, é importante que a gestão dos resíduos gerados por estas instituições seja realizada de forma eficiente e em consonância com a legislação vigente, em especial, a Lei 12.305 de 02 de agosto de 2010, que instituiu a Política Nacional de Resíduos Sólidos (PNRS). [2]

Segundo a Sociedade Brasileira de Zoológicos (SZB) existe hoje no Brasil cerca de 116 zoológicos, entre instituições públicas e privadas [3]. A Instrução Normativa IBAMA no 07/2015 [4] enquadra os zoológicos em três categorias: $A, B$ e $C$, sendo os zoológicos da categoria " $A$ " os que precisam atender a um maior e, muitas vezes complexo, conjunto de exigências.

Em termos mundiais, nove zoológicos já possuem a ISO 14.001 [5], dentre eles o Chester Zoo e o Paigton Zoo (Reino Unido) e a rede de Zoos Victoria (Austrália). Esses zoológicos promovem atitudes como a utilização de telhados verdes, aproveitamento de águas pluviais, sistemas de reciclagem e compostagem e diminuição no consumo de materiais dentre 
outras estratégias. Na América Latina a Fundação Parque Zoológico de São Paulo é a primeira a obter a ISO 14.001, sendo, portanto, o décimo zoológico no mundo com essa certificação. [6]

\section{Metodologia}

\subsection{Avaliação da Gestão dos Resíduos Sólidos nos Zoológicos Brasileiros}

Um questionário foi enviado a 116 zoológicos e aquários do Brasil para a obtenção de um diagnóstico ambiental inicial dos zoológicos brasileiros. O questionário solicitou informações quanto à destinação dos resíduos oriundos das seguintes atividades e/ou locais: folhas e galhos provenientes da varrição e poda da área externa dos parques; papel higiênico dos sanitários; detritos e restos alimentares dos recintos dos animais; restos alimentares dos restaurantes e da cozinha dos animais; carcaça de animais (recintos e veterinária); resíduos hospitalares (clínica veterinária) e material de papelaria (escritórios).

A escolha destes resíduos deve-se a experiência acumulada de 25 anos do autor relativo aos tipos de resíduos gerados nas atividades diárias nos parques zoológicos. As opções de destinação foram: compostagem, biodigestão, queima/ incineração, aterro sanitário e instituições de pesquisa (cadáveres e/ou carcaças animais para museus e universidades).

Os questionários foram respondidos por técnicos (biólogos, veterinários e zootecnistas) ou por gestores dos parques. Por questão de confidencialidade os zoológicos que contribuíram com este trabalho não foram citados, salvo os que as informações constavam em documentos públicos.

Uma vez que uma instituição pode dar uma ou mais destinação a um determinado tipo de resíduo, os valores nos gráficos podem ser superiores ao número de zoológicos participantes.

\section{2 Índice de Impacto dos Resíduos Sólidos nos Zoológicos Brasileiros}

Com a finalidade de sintetizar a avaliação da gestão dos resíduos sólidos nos zoológicos, foi criado um índice, tendo como base a origem e o destino do resíduo sólido. Os valores foram atribuídos com base nas melhores práticas de gestão dos resíduos sólidos, onde foi atribuído valor zero a forma mais adequada de destinação e dois para as consideradas mais danosas.

Exemplificando, as piores situações seriam aquelas encontradas em um zoológico que destina seus resíduos sólidos para queima / incineração (sem controle). Por outro lado, o índice indica baixo impacto quando o zoológico destina o resíduo para compostagem, biodigestão ou pesquisa. Uma vez que os resíduos oriundos de sanitários e de escritórios não podem ser destinados a compostagem, biodigestão ou pesquisa, a eles foi atribuído o valor 1 , que seria a destinação a aterros sanitários. 0 peso atribuído à destinação dos resíduos sólidos foi: Biodigestão/ Compostagem (0); Pesquisa (0); Aterro Sanitário (1) e Incineração / Queima (2).

Desta forma, o valor mínimo ficou estipulado entre 0 e o máximo 14 (todos os resíduos eram queimados). Os impactos foram divididos em 3 categoria: baixo (0 a 4); médio (5-9) e alto (1014).

\section{Resultados e Discussão}

\subsection{Avaliação da Gestão dos Resíduos Sólidos nos Zoológicos Brasileiros}

Foram avaliados 51 zoológicos, o que corresponde a aproximadamente $44 \%$ do total de 116 instituições no Brasil. Dentre os que responderam à pesquisa, dez são da categoria $A$ (20\%), 12 da categoria B (24\%) e 29 (57\%) da categoria C. As respostas indicaram que 37 (73\%) zoológicos possuem gestão pública e apenas 14 (27\%) gestão privada. Esse resultado é semelhante a outro já realizado em 2012 [7] que constatou que a maioria dos zoológicos brasileiros era de gestão pública municipal. 
A Tabela 1 apresenta a percentagem de destinação dos diferentes tipos de detritos gerados nos zoológicos brasileiros. Os dados sobre a destinação dos resíduos de varrição apontam que a compostagem/ biodigestão é realizada por $55 \%$ dos zoológicos e a destinação para aterros sanitários é realizado por $45 \%$ das instituições.

Em todos os zoológicos em diferentes épocas do ano, grandes quantidades de folhas e galhos são geradas nos parques. Este material, devidamente selecionado, pode ser destinado a compostagem diminuindo os custos com 0 recolhimento para destinação aos aterros sanitários e, ainda, gerar compostos orgânicos para utilização nos canteiros dos parques. Com relação aos recicláveis, que tenham sido inadequadamente descartados pelos visitantes nas vias dos parques, deve ser realizada a sua devida separação para coleta seletiva e, posterior recolhimento por empresa ou cooperativa de catadores de recicláveis.

No caso dos resíduos sanitários (Tabela 1), $100 \%$ desses são destinados aos aterros sanitários. Por ser material com risco de contaminação seria mais adequada sua destinação para incineração, com isso os riscos associados poderiam ser eliminados, o que não acontece com sua disposição em aterros sanitários.

Cerca de $73 \%$ dos zoológicos declararam que destinam os resíduos alimentares e dejetos animais para aterros sanitários e $27 \%$ para compostagem/biodigestão (Tabela 1). Esses resíduos gerados em quantidade ocupam grande volume nas células dos aterros sanitários. A destinação destes resíduos para compostagem pode aumentar a produção de composto orgânico e diminuir os custos com a destinação para aterros sanitários.

Atualmente isso é realizado pela Fundação Parque Zoológico de São Paulo (FPZSP) em sua Unidade de Processamento de Composto Orgânico (UPCO). Essa boa prática diminuiu a quantidade de orgânicos (varrição, restos alimentares humanos e animais, camas de animais, estrume) que ficam temporariamente depositados, aguardando o recolhimento para destinação definitiva. Com isso diminui-se a quantidade de vetores que são atraídos às áreas de transbordo temporário e podem causar danos à saúde humana e animal. A alternativa de compostagem/biodigestão tende a diminuir a pressão sobre os aterros sanitários, sendo destinadas apenas pequenas quantidades que sejam realmente inservíveis. A FPZSP teve significativos benefícios de ordem econômica e ambiental após a entrada em operação da sua UPCO, pois houve redução nos gastos com insumos, tais como fertilizantes e adubos sintéticos. [8]

A Tabela 1 ainda indica que a maior parte dos zoos destinam seus resíduos alimentares humanos, provenientes de restaurantes e lanchonetes para aterros sanitários. Esta é uma prática prevista, mas não a mais indicada. A destinação para compostagem/biodigestão deste tipo de resíduos é realizada por $26 \%$ dos zoológicos. O aumento na destinação para compostagem seria uma ação interessante para diminuir a pressão sobre os aterros sanitários e aumentar a produção de composto orgânico para utilização nas áreas verdes dos parques.

Tabela 1: Percentagem (\%) de destinação dos diferentes tipos de resíduos sólidos nos zoológicos brasileiros $(n=51)$

\begin{tabular}{lcccc}
\hline Resíduos & \multicolumn{5}{c}{$\begin{array}{c}\text { Percentagem da destinação } \\
\text { aterro } \\
\text { sanitario }\end{array}$} & $\begin{array}{c}\text { Compostagem / } \\
\text { biodigestão }\end{array}$ & $\begin{array}{r}\text { queima / } \\
\text { incineração }\end{array}$ & pesquisa \\
\hline - folhas e galhos & 55 & 45 & 0 & 0 \\
- papel higiênico dos & 100 & 0 & 0 & 0 \\
sanitários & & & & \\
- detritos dos recintos & 73 & 27 & 0 & 0 \\
- restos alimentares dos & 74 & 26 & 0 & 0 \\
$\quad$ restaurantes & & & & \\
- carcaça de animais & 30 & 7 & 27 & 36 \\
- resíduos hospitalares & 65 & 0 & 35 & 0 \\
- material de escritório & 98 & 2 & 0 & 0 \\
\hline
\end{tabular}

É importante citar que pela PNRS em seu Art. 9o [2], a disposição final ambientalmente adequada deve ser realizada para os rejeitos e não para os resíduos. Sendo assim, a destinação de resíduos sólidos aos aterros sanitários está contrária à Lei. Como exemplo de boas práticas em zoológicos no exterior pode ser citado o zoo 
de Melbourne, Austrália, que reduziu em 38\% a quantidade enviada de resíduos orgânicos para aterros sanitários somente incrementando seu programa de compostagem [9].

Quanto às carcaças animais (Tabela 1 ) foi observado que $36 \%$ dos zoológicos enviam este material para instituições de pesquisa, 30\% destinam o resíduo para aterros sanitários, $27 \%$ fazem a destinação para queima/incineração e $7 \%$ destinam para compostagem/ biodigestão. A destinação inadequada deste resíduo pode configurar riscos à saúde devido aos patógenos que podem estar presentes nas carcaças e cadáveres de animais.

Apesar da destinação para fins científicos ser a prática mais difundida, é importante ressaltar que dependendo da causa do óbito o cadáver ou carcaça não deve ser encaminhado para museus ou instituições de ensino superior devido ao risco de contaminação. Uma destinação interessante é a utilizada pela FPZSP onde os cadáveres de animais, após serem reduzidos na sala de necropsia, são destinados para UPCO [10]. Devese, no entanto, estar alerta para a legislação vigente quanto à disposição de carcaças e cadáveres. Os resíduos em questão encontramse no subgrupo A4 da ANVISA/RDC 222/18 [11] que explicita que estes resíduos podem ser dispostos, sem tratamento prévio, em local devidamente licenciado para disposição final de RSS. Já a Resolução Conjunta (RC) $01 / 04$, do Estado de São Paulo [12] enquadra esses resíduos no Grupo $F$, que exige tratamento prévio à disposição, sendo proibido o envio desse resíduo para processo de compostagem.

Sendo assim, os pareceres se opõem quanto ao reaproveitamento das carcaças de animais para compostagem. Para utilizar o composto a partir de carcaças a FPZSP obteve autorização da Secretaria de Defesa Agropecuária, no 27/2006 [13], que especifica os parâmetros para que o produto final seja considerado como fertilizante orgânico. Após levantamento realizado em granjas, Andreazzi [14] cita que atualmente as formas de destinação de carcaças de animais mortos incluem, principalmente, compostagem e fossas sépticas. Mesmo animais que tenham vindo a óbito com suspeitas de alguma doença e que se enquadrariam no grupo A2 da ANVISA/RDC 222/18 [11] podem ser destinados para compostagem. Durante a compostagem, as altas temperaturas alcançadas eliminam os patógenos, eliminando o risco que o material contaminado possa causar danos à saúde ambiental, humana e animal. No tocante à disposição final de carcaças e cadáveres, ainda é comum a disposição em fossas sépticas, enterramento e incineração. Porém, a compostagem ainda é o método ambientalmente mais eficiente, pois pode gerar receita se bem conduzido e evitando a contaminação do solo, do ar e da água. Nesse sentido, Neto [15] ressalta que são necessários, no mínimo, 20 dias sob temperatura de aproximadamente $60{ }^{\circ} \mathrm{C}$, para que se obtenham índices satisfatórios de eliminação de microrganismos patógenos no processo de compostagem.

Dos zoológicos avaliados, 65\% informaram que resíduos de serviços de saúde (RSS) oriundos dos hospitais ou clínicas veterinárias vão para aterros sanitários, via empresas públicas ou particulares de limpeza urbana (Tabela 1) e 35\% vão corretamente, para a queima/incineração, conforme determina a legislação. De acordo com a Resolução da Diretoria do Colegiado da Agência Nacional de Vigilância Sanitária (RDC ANVISA) no 222/18 [11] e a Resolução do Conselho Nacional de Meio Ambiente (CONAMA) no 358/05 [16] os RSS são classificados em cinco grupos em função de suas características e consequentes riscos que podem acarretar ao meio ambiente e à saúde. Excetuando o Grupo C (resíduos radioativos), os demais podem ser observados no cotidiano das áreas de atendimento veterinário nos zoológicos: Grupo A (resíduos com a possível presença de agentes biológicos que, por suas características, podem apresentar riscos de infecção), Grupo B (resíduos químicos), Grupo D (resíduos comuns) e Grupo E (materiais perfuro cortantes).

Cabe ressaltar que no Art. 27, § 10 da PNRS [2] fica definido que o gerador (pessoas físicas ou jurídicas referidas no Art. 20) não fica isento de responsabilidades por danos causados por gerenciamento inadequado dos rejeitos ou resíduos sólidos mesmo tendo contratado serviços de coleta, armazenamento, transporte, 
transbordo ou destinação final de resíduos sólidos ou de disposição final de rejeitos. Sendo assim, o acompanhamento das ações supracitadas pelos zoológicos é de suma importância para que não sejam responsabilizados solidariamente em caso do não cumprimento das regras pela empresa prestadora do serviço.

No que se refere aos resíduos de escritório (papelaria) nos zoológicos brasileiros estes são destinados, predominantemente, a aterros sanitários (98\%)(Tabela 1). Uma pequena percentagem (2\%) declarou a destinação para compostagem/biodigestão, o que em um primeiro momento parece pouco provável. No dia a dia a reutilização de papel usado deve ser estimulada para confecção de blocos para anotações, uso do verso da folha e impressões em ambos os lados aumentam a vida útil de uma folha. Uma vez que os resíduos de escritório possuem potencial para reciclagem (papéis, papelão, plásticos, vidros) esta boa prática deve ser incentivada nas instituições. Com isso cerca de três metros cúbicos, em cada tonelada de papel reciclável, deixaria de ser descartado nos aterros segundo a cartilha da A3P. [17]

As Figuras 1 a 3 ilustram a relação entre às três categorias de enquadramento dos zoológicos e o tipo de destinação dada aos resíduos. Para os zoológicos enquadrados na categoria $A$, resíduos de varrição (folhas e galhos) são destinados na mesma proporção para compostagem (50\%) e aterros sanitários (50\%). Os resíduos sanitários (papel higiênico) são destinados $100 \%$ a aterros sanitários. Resíduos oriundos de detritos animais encontrados dentro do recinto dos animais são destinados em 50\% para compostagem e 50\% para aterros sanitários. Os restos alimentares dos restaurantes e cozinhas são destinados em $45 \%$ para compostagem e $55 \%$ para aterros sanitários. No tocante a destinação de carcaças de animais mortos, a pesquisa aparece com $38 \%$, seguida de aterro sanitário com $31 \%, 23 \%$ a destinam para incineração e $8 \%$ para compostagem. Os resíduos de serviços de saúde são destinados em $75 \%$ a aterros sanitários e $25 \%$ para queima/incineração. Os resíduos de escritório são destinados em $100 \%$ para aterros sanitários.
Figura 1 - Percentagem de indicações dos zoológicos brasileiros de categoria $A(n=10)$, para cada tipo de destinação de resíduos sólidos. (Preto: aterro sanitário; Branco: compostagem/biodigestor; cinza: pesquisa; azul: queima/incineração)

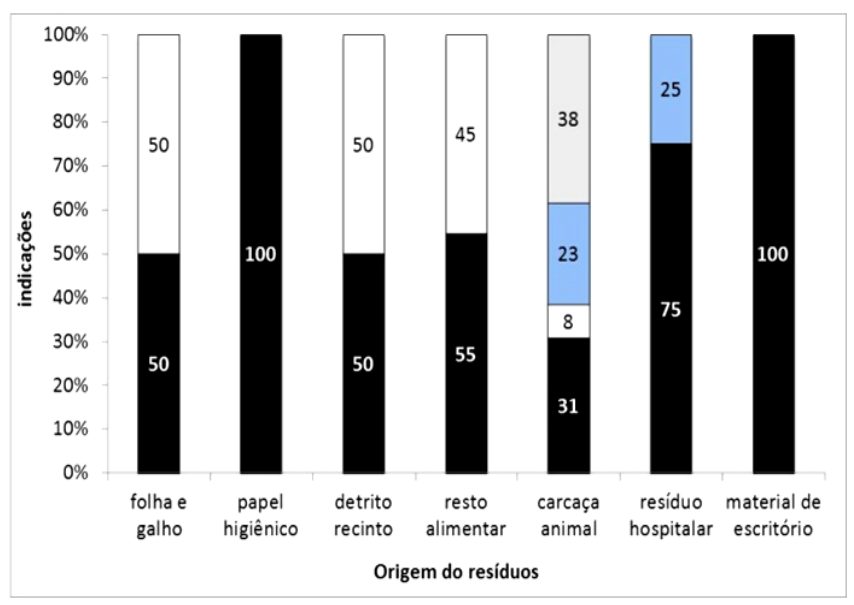

Os dados obtidos referentes aos zoológicos enquadrados na categoria B (Figura 2) demonstram que $69 \%$ dos resíduos de varrição são destinados para aterros sanitários e 31\% para compostagem. Para os resíduos sanitários a destinação aos aterros sanitários é de 100\%.

Figura 2 - Percentagem de indicações dos zoológicos brasileiros de categoria $B(n=12)$, para cada tipo de destinação de resíduos sólidos. (Preto: aterro sanitário; Branco: compostagem/ biodigestor; cinza: pesquisa; azul: queima/incineração

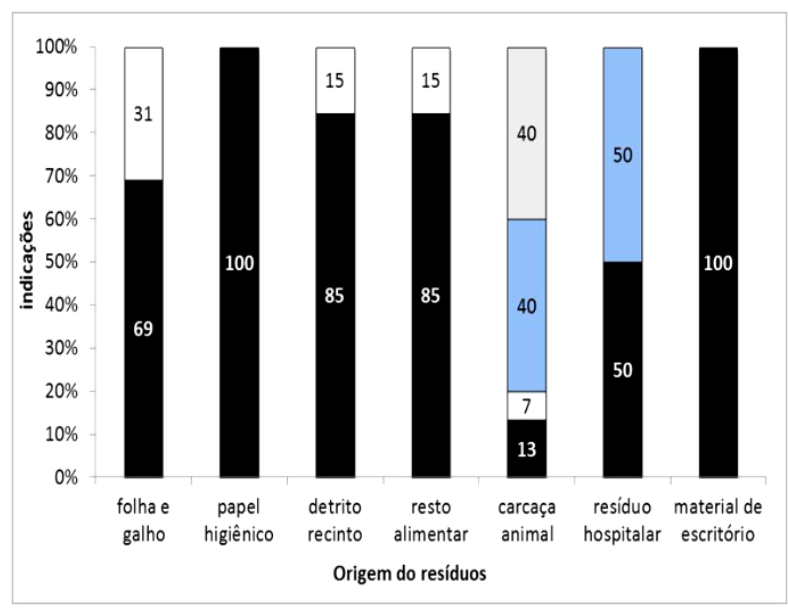

Os resíduos oriundos dos detritos e restos dos recintos dos animais e também os resíduos alimentares dos restaurantes e cozinha dos 
animais são destinados em $85 \%$ para aterros sanitários e $15 \%$ são destinados para compostagem. Resíduos oriundos de carcaças de animais são destinados em $40 \%$ para pesquisa e $40 \%$ para queima/incineração, sendo $13 \%$ destinados para aterros sanitários e 7\% para compostagem. Os resíduos hospitalares são queimados, incinerados (50\%) ou destinados a aterros sanitários (50\%). Os resíduos de escritório são destinados em $100 \%$ para aterros sanitários.

Os zoológicos enquadrados na categoria $C$ (Figura 3), no que se refere aos resíduos de varrição, $52 \%$ destinam esses resíduos para aterros sanitários, ficando $48 \%$ para a realização de compostagem. Resíduos sanitários são destinados em $100 \%$ para os aterros. Restos e detritos de animais são destinados em $75 \%$ para aterros sanitários, ficando $25 \%$ para compostagem ou biodigestor. Os restos alimentares são destinados em $76 \%$ para compostagem em menor percentagem (24\%) para aterro. As carcaças de animais são destinadas para pesquisa em $32 \%$, a destinação de $39 \%$ é para aterros sanitários, ficando $21 \%$ destinados a aterros sanitários e 7\% para queima/incineração. Os resíduos hospitalares são incinerados em $69 \%$ dos casos e $31 \%$ são destinados para queima/incineração. Os resíduos de escritório são destinados em 96\% para aterro sanitário e $4 \%$ são destinados a compostagem.

Figura 3 - Percentagem de indicações dos zoológicos brasileiros de categoria $C(n=29$, para cada tipo de destinação de resíduos sólidos. (Preto: aterro sanitário; Branco: compostagem/ biodigestor; cinza: pesquisa; azul: queima/ incineração)

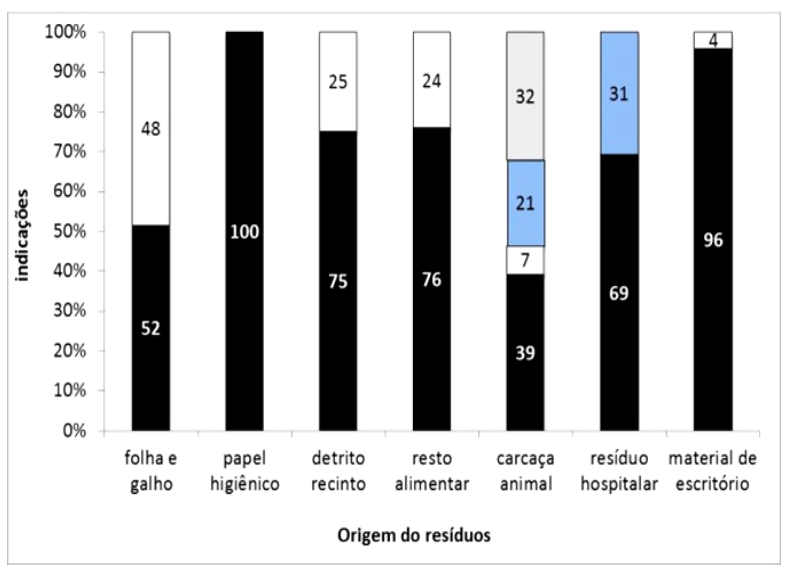

Em todas as categorias de enquadramento dos zoológicos ainda predomina a tendência na destinação dos resíduos para aterros sanitários. De uma forma geral, as instituições que responderam denotam seguir algumas regras na destinação dos resíduos sólidos gerados. Porém, ainda estão muito aquém do ideal. Uma exceção é a Fundação Parque Zoológico de São Paulo (FPZSP) que possui implantado um Sistema de Gestão Ambiental certificado pela ISO 14.001.

Augusto e Nassar [18] avaliaram a origem e destinação dos resíduos sólidos na Fundação RIOzoO, um zoológico de categoria $A$ e de administração pública municipal (na ocasião do estudo). Neste estudo realizado em diferentes áreas (Administração/Apoio, Limpeza, Manutenção, Biologia e Veterinária) evidenciou que a Fundação não realiza, em grande parte a segregação adequada dos resíduos sólidos gerados no parque. Sendo a maior parte dos resíduos destinados a aterros sanitários. $O$ estudo aponta a origem e o tipo de resíduos, indicando a forma atual de destinação e sugerindo novas abordagens, dentre elas a criação de uma área de compostagem na instituição e o incentivo a coleta seletiva dos resíduos.

Segundo Barreto e colaboradores [19], a gestão de resíduos não resulta apenas em ganhos ambientais, como também econômicos e sociais para as empresas. Com essa gestão é possível mitigar os custos das despesas empresariais como conta de luz, água, dentre outros. O que possibilita a redução do preço dos serviços oferecidos pela empresa. Além da questão diretamente econômica, a reciclagem de resíduos auxilia a criar um ambiente mais agradável para funcionários, com bônus ou mesmo confraternizações, levando-os a se sentirem mais importantes e valorizados, por contribuírem diretamente no desenvolvimento do país.

Em uma visão geral, deve-se estimular a prática dos $5 R^{\prime}$ s em todos os setores, e um maior incremento na compostagem dos resíduos orgânicos, como exemplo do que já acontece na FPZSP. Tal destinação, certamente iria diminuir a destinação para os aterros sanitários e, 
consequentemente, já poderia ser considerado um ganho ambiental significativo. A FPZSP tem sido um exemplo positivo de gestão de resíduos sólidos desde a implantação da UPCO em 2003 [20]. A UPCO é composta por 44 células de tratamento que processam restos de alimentos, fezes, camas de animais, resíduos de podas e carcaças de animais. O composto orgânico produzido é utilizado na Divisão de Produção Rural e nos canteiros, praças e viveiros do Parque Zoológico e Zoo Safari.

Com essa ação, a quantidade de resíduos sólidos destinados para aterros sanitários teve uma enorme diminuição. Outro aspecto positivo é a redução dos grandes volumes de resíduos no parque até sua retirada para os aterros sanitários e, consequentemente, redução da presença de vetores no local. Com essa prática houve uma melhora na qualidade das condições ambientais locais e do entorno. Outro aspecto positivo seria a redução do custo com o transporte de resíduos e sua disposição. A FPZSP através de suas iniciativas é um modelo que pode ser seguido por outros zoológicos (públicos ou privados) para melhoria da qualidade ambiental e atendimento a PNRS.

Alguns zoológicos no exterior possuem Planos de Gestão Ambiental implantados. No Reino Unido o Paignton Zoo, que foi o terceiro zoológico no mundo a ter a ISO 14.001, são realizadas auditorias internas e externas anualmente para manter o sistema funcionando. As práticas sustentáveis diminuíram o consumo de energia e água o que levou a redução de custos. [21]

O Colchester Zoo no Reino Unido vem trabalhando para reduzir, reutilizar e reciclar resíduos através de coleta e reciclagem de metais e vidros, além da cobrança por sacolas plásticas. O Reino Unido tem uma meta de redução de material enviado para aterros até 2020 e vem aumentando as taxas para depósito em aterros sanitários. O Colchester Zoo tem gerado energia a partir da queima de resíduos que é convertida em energia elétrica (recuperação de energia). O dióxido de carbono da queima vai para a atmosfera, mas o resíduo no aterro geraria metano que é pior para o aumento do aquecimento global. As cinzas são enviadas para construção de rodovias e agregados para a construção civil. [22]

O London Zoo mantém contrato com uma empresa que realiza a gestão ambiental do zoológico. Essa empresa já conseguiu evitar que 98\% dos resíduos provenientes deste e do Parque de Safari Whipsnadek chegassem aos aterros. Os $2 \%$ restantes, provenientes de resíduos incinerados (cinzas), são destinadas aos aterros. O principal esforço foi em relação a enorme quantidade de fezes produzidas anualmente. Uma das soluções encontradas foi usar as fezes de herbívoros na compostagem e produção de adubo. Já as fezes de carnívoros são enviadas para as estações de digestão anaeróbica, em cidades vizinhas, para conversão em energia. Além das fezes a empresa lida com 22 rotas de diferentes resíduos, inclusive resíduos perigosos, restos clínicos, além de material reciclável proveniente dos visitantes. [23]

Os Zoos de Victoria, na Austrália [9] vem buscando tornar suas ações ambientalmente sustentáveis e responsáveis, com políticas de prevenção de poluição através da implantação de um sistema de gestão ambiental e práticas sustentáveis (possui a ISO 14.001 desde 2012). Eles possuem ainda a intenção de diminuir a sua "pegada ecológica" com ações como:

- Minimizar a produção de gases de efeito estufa por meio de práticas eficientes de utilização da energia, utilização de veículos movidos a eletricidade, e investimento em energias renováveis;

- Compensação de emissões de gases de efeito estufa residuais;

- Colocar em prática uma política de contratos públicos ecológicos e diretrizes para a compra com a prevenção de resíduos;

- Completar o ciclo de reciclagem e a redução dos impactos através do entendimento do ciclo de vida de suas operações;

- Reduzir o aporte de resíduos para aterro por meio de redução de resíduos, reutilização e reciclagem;

- Minimizar o uso de água através de seu uso eficiente, design de instalações e reciclagem; 
- Utilizar a análise do ciclo de vida para melhorar suas operações, minimizar impactos ambientais negativos $\mathrm{e}$ desenvolver práticas sustentáveis;

- Formar pessoal de apoio para reduzir os impactos ambientais no local de trabalho;

- Uma forma de avançar nas metas e tornar os resultados visíveis através do monitoramento constante e de auditorias anuais, com a publicação no relatório anual.

A compostagem reduziu $38 \%$ dos resíduos destinados a aterros proveniente do Zoológico de Melbourne [24]. Também na Austrália, o Taronga Zoo produz cerca de 35 toneladas de resíduos por mês, sendo que apenas $20 \%$ dos resíduos gerados pelo público vão para aterros. A organização utiliza o princípio dos 4R's, reduzir, reutilizar, reciclar e recusar, aonde os funcionários atuam para: reciclar papel e papelão; usar papel picado dos escritórios para camas de animais; reutilizar a serragem para "cenários"; retornar caixas de madeira e papelão para os fornecedores, reciclar tonners e baterias, reduzir restos alimentares pelo uso de compostagem e minhocário. [25]

A FPZSP implementou como pilar do Sistema de Gestão Ambiental (SGA), a Política Ambiental da Fundação, documento que traz os princípios a serem conhecidos e seguidos por todos os funcionários e colaboradores e que visam, principalmente, à conservação de espécies e da natureza, à prevenção e controle da poluição, à conscientização ambiental de funcionários e visitantes, ao cumprimento da legislação ambiental e à melhoria contínua do sistema. Adotou medidas para a preservação e controle da poluição desde 2007 [26], obtendo assim a certificação da ISO 14.001. Sendo o 10 zoológico no mundo a receber essa certificação, e o primeiro da América Latina.

\section{2 Índice de Impacto Ambiental dos Resíduos Sólidos nos Zoológicos}

Aproximadamente $65 \%(n=33)$ dos zoológicos brasileiros possuem impacto médio em relação aos resíduos sólidos, seguido de $22 \%$ com impacto alto $(n=11)$ e $14 \%$ com impacto Baixo $(n=7)$.

A representação do Índice de Impacto por tipo de gestão apresentado na Figura 4 mostra que nas gestões pública e privada predominam o índice indicativo de impacto médio.

De forma geral, o predomínio do impacto médio em todas as categorias de zoológicos ( $A, B$ e C) demonstra a necessidade de melhores práticas de destinação visando à melhoria na gestão dos resíduos sólidos gerados.

Figura 4 - Percentagem do índice de impacto por tipo de administração (público ou privado) e categoria dos zoológicos do Brasil (A, B ou C). Vermelho: impacto alto; amarelo: impacto médio; verde: impacto baixo

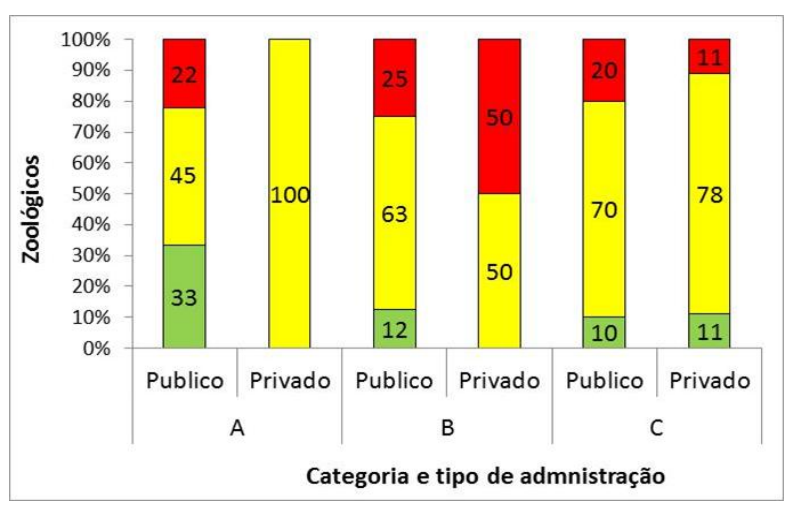

\section{Conclusões}

Os zoológicos brasileiros não realizam em grande parte segregação adequada de seus resíduos e, em sua maioria, tendem a enviá-los para serem dispostos em aterros sanitários. $\mathrm{O}$ cenário não varia muito se a avaliação é feita distinguindo administração pública ou privada ou diferentes categorias ( $A, B$ e $C$ ).

A destinação para fins científicos não é suficiente para dar destinação a todos os cadáveres de animais de um zoológico. Apesar da legislação não ser clara, a melhor destinação no caso dos zoológicos seria a compostagem ou a biodigestão. A compostagem é o método mais barato e por esse motivo um dos mais viáveis a ser implementado, desde que não ocorra a contaminação do composto gerado, por agentes patogênicos.

Apesar de algumas tendências de realização de coleta seletiva, reciclagem e compostagem 
serem feitas, essas iniciativas não são suficientes para diminuírem os impactos causados, pois ainda não são implementadas em larga escala. Por serem grandes geradores de resíduos os zoológicos devem atender melhor a Política Nacional de Resíduos Sólidos, no tocante a melhor segregação dos resíduos gerados.

É muito importante que os zoológicos brasileiros, independentes do tipo de gestão, façam a adesão a A3P o que, consequentemente, facilitará a implantação de um Sistema de Gestão Ambiental nos parques. A implantação deste sistema pode indicar o nível de comprometimento e envolvimento com a causa ambiental de uma instituição, contribuindo ainda para a sanidade e o bem-estar dos animais, colaboradores e visitantes. A atual situação não é alarmante, porém, ainda não é o desejável.

\section{Referências}

[1] Z. S. Cubas. Tratado de animais selvagens - medicina veterinária / Zalmir Silvino Cubas, Jean Carlos Ramos Silva, José Luiz Catão-Dias. São Paulo: Roca, 2006.

[2] Brasil. Lei $n^{\circ} 12.305$, de 02 de agosto de 2010. "Institui a Política Nacional de Resíduos Sólidos"; altera a Lei $\mathrm{n}^{\circ} 9.605$, de 12 de fevereiro de 1998; e dá outras providências. Diário Oficial da União, seção 1. Brasília, terça-feira, 03 de agosto de 2010. Disponível em: <http://www.planalto.gov.br/ccivil_03/_ ato2007-2010/2010/lei/|12305.htm>. Acesso em: $09 \mathrm{jul} / 2016$.

[3] <http://www.szb.org.br/arquivos/zoos-eaquarios-brasil.pdf> . Acesso em: 26 jan/2016.

[4] Brasil. Instrução Normativa IBAMA № 07/2015, de 30.Abr.2015. "Institui e normatiza as categorias de uso e manejo da fauna silvestre em cativeiro, e define, no âmbito do Ibama, os procedimentos autorizativos para as categorias estabelecidas". Disponível em: <https://www.ibama.gov.br/phocadownload/fau na/

faunasilvestre/2015_ibama_in_07_2015_autoriza cao_uso__fauna_empreendimentos.pdf> Acesso: $15 \mathrm{mar} / 2019$.

[5] ASSOCIAÇÃO BRASILEIRA DE NORMAS TÉCNICAS. NBR ISO 14001. Sistemas de gestão ambiental - ABNT.2015.

[6]<http://www.saopaulo.sp.gov.br/spnoticias/ul timas-noticias/ zoologico-paulista-e-o-10-nomundo-a-conseguir-a-certificacaoiso-14001> . Acesso em 28 de nov/2018.

[7] F.S.Magnani. Panorama dos Jardins Zoológicos Brasileiros - Números, Verdades e Mitos, São Carlos. p.30, 2012.

[8] <www.premiomariocovas.sp.gov.br> . O Processo de compostagem como instrumento de preservação ambiental na Fundação Parque Zoológico de São Paulo. Disponível em: Acesso em: $12 \mathrm{fev} / 2015$.

[9] <www.zoo.org.au> . Acesso em: 24 ago/2016.

[10] M.L.M. Roque, R.T. Malheiros, S.S. Martinelli. Compostagem como técnica de reciclagem do subgrupo $A 4$, carcaças e cadáveres de animais de médio e grande porte, sob a luz da RDC 306/2004 da ANVISA. V Congresso Brasileiro de Gestão Ambiental - Belo Horizonte/MG - 24 a 27/11/2014.

[11] Resolução ANVISA/RDC 222, de 28 de março de 2018, que regulamenta as Boas Práticas de Gerenciamento dos Resíduos de Serviços de Saúde. Disponível em:

<http://portal.anvisa.gov.br/documents/33852/2 $71855 /$

RDC+222+de+Mar\%C3\%A7o+de+2018+COMENTA DA/ edd85795-17a2-4e1e-99ac-df6bad1e00ce> . Acesso em 15 mar/2019.

[12] RESOLUÇÃO CONJUNTA SS/SMA/SJDCSP N. 1, DE 15.07.2004

[13] Secretaria de Defesa Agropecuária, no 27/2006. Disponível em: <http://igeologico.sp.gov.br/wp- 
content/uploads/ cea/Res.SS-SMA-SJDC0104.pdf>.

[14] M. A. Andreazzi, J. M. G. Santos, R. M. J. Lazaretti. Destinação dos resíduos da suinocultura em granjas das regiões noroeste e sudoeste do Paraná. Revista Eletrônica em Gestão, Educação e Tecnologia Ambiental Santa Maria, 19(3), p.744-751, 2015.

[15] J.T.P Lelis Neto. III-021 - A Contaminação M. de P.N.; Biológica na Compostagem. 21ㅇ Congresso Brasileiro de Engenharia Sanitária e Ambiental, João Pessoa, 2001.

[16] Brasil. Resolução CONAMA n. 358/2005 "Dispõe sobre o tratamento e a disposição final dos resíduos dos serviços de saúde e dá outras providências." 29/04/2005. Disponível em: <http://www2.

$\mathrm{mma} . g o v . b r / p o r t / c o n a m a / l e g i a b r e . c f m$ ?codlegi= 462>. Acesso: 28 nov/2018.

[17] BRASIL.; A3P - Agenda Ambiental na Administração Pública, Brasília, p.63, 2009. Disponível em: <http://www.mma.gov.br/estruturas/a3p/_arqui vos/cartilha_ a3p_36.pdf> . Acesso em 19 mar/2019.

[18] A.M. Augusto C.A.G. Nassar. Gestão dos resíduos sólidos na Fundação RIOZOO (Rio de Janeiro-RJ). Anais do VIII Congresso Brasileiro de Gestão Ambiental, Campo Grande/ MS (27 a 30/11/2017). 1-6p. 2017

[19] S.M.Barreto Jr., T.S.R. Paz, Y.B. Kevorkian, E. P. Andrade. Gestão de resíduos no escritório: melhorando o local de trabalho e mobilizando pessoas. XXXV Encontro Nacional de Engenharia de Produção, Perspectivas Globais para Engenharia de Produção - Fortaleza, CE, Brasil, 13 a 16 de outubro de 2015. Disponível em: <http://www.abepro.org. br/> . Acesso em: 24 ago/2017.
[20] J.B. Cruz, O Processo de Compostagem como Instrumento de Preservação Ambiental na Fundação Parque Zoológico de São Paulo (FPZSP), Pôster apresentado no I Simpósio sobre compostagem, ciência e tecnologia, na UNESP de Botucatu-SP em 19-20 de agosto de 2004.

[21]<https://www. paigntonzoo.org.uk/conservati on/environmental- management\%3E . Acesso em: 05 fev/2016.

[22]<https://www.colchesterzoo.com/conservati on/the-greenzoo\#> . Acesso em: 28 nov/2018.

[23]<https://www.businessgreen.com/bg/news/2 191617/londonzoo-closes-in-onzero-waste-goalthanks-to-poo-power > . Acesso em: 28 nov/2018

[24] <https://www.zoo.org.au> . Acesso em: 24 ago/2016.

[25] <https://www.taronga.org.au> . Acesso em: $07 \mathrm{fev} / 2016$.

[26] <https://www.ambiente.sp.gov.br> . Acesso em: 20 out/2015.

* Cristina Nassar é coordenadora do Programa de Engenharia Ambiental (PEA/POLI-UFRJ) e Anderson Mendes Augusto é da Fundação RIOZOO 
